\title{
Correlation analysis of cortisol concentration in hair versus concentrations in serum, saliva, and urine
}

\author{
Łukasz Cieszyński ${ }^{\oplus}$, Jarosław Jendrzejewski, Piotr Wiśniewski, Przemysław Kłosowski, \\ Krzysztof Sworczak
}

Department of Endocrinology and Internal Diseases, Medical University of Gdansk, Gdansk, Poland

\begin{abstract}
Introduction: Cortisol concentration is measured in blood, urine, and saliva samples. It has been recently proven that cortisol could also be detected in hair samples. Cortisol measurements in different samples have their own individual characteristics and clinical utility. We aimed to investigate the correlation between hair cortisol concentration and standard cortisol measurements used in clinical practice. Material and methods: Fifty adult volunteers with a negative history of endocrine disorders were enrolled in the study. Morning serum cortisol (MSC), evening serum cortisol (ESC), evening free salivary cortisol (EFSC), urine free cortisol (UFC), and hair cortisol concentration (HCC) were analysed in all participants. Eventually, 41 volunteers were included into the study, whose cortisol concentration in the $1 \mathrm{mg}$ overnight dexamethasone suppression test (1 mg ONDST) were $<50 \mathrm{nmol} / \mathrm{L}$, and cortisol levels in serum, saliva, and urine were within reference ranges. Hair cortisol concentration test was performed for $20 \mathrm{mg}$ of hair strands of the proximal $1 \mathrm{~cm}$ hair segments. Results: Hair cortisol concentration ranged from 0.3036 to $2.65 \mathrm{nmol} / \mathrm{mg}$, and the average value was $0.8125 \pm 0.4834 \mathrm{nmol} / \mathrm{mg}$. No significant correlations were found between HCC and MSC ( $r h o=0.04419, \mathrm{p}=0.7838$ ), HCC and ESC ( $\mathrm{rho}=-0.2071, \mathrm{p}=0.1938$ ), HCC and EFSC (rho $=0.1005, \mathrm{p}=0.532)$, or HCC and UFC ( $\mathrm{rho}=0.1793, \mathrm{p}=0.262)$.

Conclusions: This work is another step in the discussion on the application of HCC determinations in clinical practice. Our results have showed no correlations between HCC and single point cortisol assessment in blood, saliva, and urine in patients with reference cortisol levels. (Endokrynol Pol 2020; 71 (6): 539-544)
\end{abstract}

Key words: hair cortisol; serum cortisol; salivary cortisol; urine cortisol; cortisol assessment; cortisol correlation

\section{Introduction}

Evaluation of disorders of the hypothalamic-pituitary-adrenal axis (HPA) is often challenging in endocrine diagnostics. The most common pathologies of HPA include Cushing's syndrome/disease (overt, subclinical, cyclic, and iatrogenic), primary/secondary adrenal insufficiency, and assessment of possible hormonal adjustment in patients receiving glucocorticosteroids (GCS) substitution doses [1, 2]. In addition, pseudo-Cushing's syndrome in the course of e.g. depression, alcoholism, type 2 diabetes, abdominal obesity, or polycystic ovary syndrome is also an important diagnostic challenge $[3,4]$. Cortisol concentration is routinely measured in blood, urine, and saliva samples. It has been recently shown that cortisol could be also detected in hair samples. Cortisol measurements in different samples have their own individual characteristics and clinical utility.

The determination of serum cortisol mostly refers to its total fraction (serum total cortisol, STC), including cortisol bound to plasma proteins like transcortin (cortisol binding globulin, $\mathrm{CBG}$ ), but also to sex hormone binding globulin (SHBG) and albumin [5, 6]. Hence, non-primary HPA-related factors may influence the laboratory measurements. Oral contraception, pregnancy, or hyperthyroidism increase STC level (false positive results), while significant hypoalbuminaemia $<25 \mathrm{~g} / \mathrm{dL}$ lowers STC concentration (false negative results) [5-8]. Serum free cortisol (SFC) measurement is not routinely performed. It is assumed that SFC constitutes about $3-5 \%$ of the total cortisol fraction [7]. Serum cortisol levels are tested in the morning, evening, and night hours, in order to assess its circadian rhythm of secretion. The absence of circadian cortisol rhythm is one of the first manifestations of endogenous hypercortisolaemia. Therefore, circadian cortisol measurement is one of the first-line tests in the assessment of HPA disorders. However, determination of cortisol concentrations at night might be difficult for outpatient departments due to the working hours of laboratories. Serum cortisol is also assessed in dexamethasone suppression test, Synacthen stimulation test, corticotrophin releases hormone (CRH), or vasopressin stimulation tests used in the diagnosis and differentiation of cortisol level disorders $[8,9]$. 
The determination of cortisol in saliva reflects its free fraction (free salivary cortisol, FSC) because its presence in saliva is the result of passive diffusion of SFC from the blood into saliva. The same amount of cortisol is converted to cortisone in the salivary glands by 11b-hydroxysteroid dehydrogenase type 2 (11bHSD2). Therefore, FSC concentrations are lower than serum cortisol. It is assumed that FSC constitutes about $50-70 \%$ of SFC [10]. A saliva sample collection is a stress free non-invasive procedure, and it does not require the involvement of medical personnel; hence, it is cost effective and minimises the impact of stress-induced hypercortisolaemia related to hospitalisation and invasive derivation of blood samples. Furthermore, cortisol in saliva is stable at room temperature for up to seven days, which allows a sample to be taken at any time of the day of night. This in turn allows easy analysis of the circadian rhythm of cortisol. All this makes the assessment of cortisol in saliva a very good screening test for cortisol level deviation [11, 12].

In the past, urine free cortisol (UFC) was recognised as the main test (gold standard) in cortisol secretion disorder assessment. Currently it is used as a complementary assay. Similar to salivary cortisol, UFC concentrations are also significantly reduced due to the renal activity of 11bHSD2 [13]. Difficulties in assessing UFC include frequent interference of determinations with drugs or GCS metabolites, such as prednisolone, methylprednisolone, spironolactone, dexamethasone, cortisone, 17-hydroxyprogesterone, or carbamazepine. In addition, patients' self-urine collection is not always properly performed, which in turn might affect UFC results. In patients with renal failure (glomerular filtration rate $[\mathrm{GFR}]<30 \mathrm{~mL} / \mathrm{min}$ ), it is possible to obtain false negative results. Due to these disadvantages, instead of UFC assessment it has been suggested to measure the cortisol:creatinine ratio in a single urine sample [14].

Hair cortisol concentration (HCC) assessment is not routinely performed due to a number of pre-laboratory impairing factors. The first determinations of HCC in humans were described in 2004 [15]. Considering the average hair growth of $1 \mathrm{~cm}$ per month, a hair sample, depending on its length, might reflect cortisol levels over the last days, weeks, or months [16]. An additional benefit of the HCC assessment is the non-invasive sample collection, and the ability to store it at room temperature for an extended period of time without any preparation [17]. The presence of cortisol in hair, like other endogenous substances and xenobiotics, is the result of the passive diffusion of free cortisol from the blood to the hair matrix during its formation in the bulb [18]. In addition, a certain amount of cortisol may come from sweat and sebum. Therefore, HCC may depend on additional factors, such as gender (stimulation of sweat and sebum production by androgens), age (slower hair growth with age), dyeing hair (possible leaching of cortisol by chemical agents, interference in the assay), physical activity, hygiene habits (frequency of hair washing), or exposure to sunlight [19-25]. One study demonstrated the possibility of cortisol production by hair bulb cells [26]. HCC determinations are performed by liquid chromatography tandem-mass spectrometry (LC-MS/MA) or immunoenzymatic assays [27, 28]. Assessment of HCC in healthy volunteers versus standard blood cortisol measurement methods was presented in our previous work [29]. Here we present analysis of HCC correlation with cortisol concentrations in blood, saliva, and urine in individuals with no HPA disorders.

\section{Material and methods}

All participants gave written informed consent. The study was approved by the Bioethics Committee at the Medical University of Gdansk.

Fifty adult volunteers with a negative history of endocrine disorders were enrolled into the study. Subjects treated with GCS over the past year prior to the enrolment were excluded from the study. Whole blood ( $3 \mathrm{~mL}$ ) was collected at 8.00 a.m. and 8:00 p.m. on the same day to assess serum total cortisol concentration in the morning (morning serum cortisol, MSC) and evening (evening serum cortisol, ESC), respectively. In order to assess the daily excretion of UFC, $24 \mathrm{~h}$ urine collection under medical supervision was done, and $5 \mathrm{ml}$ of urine sample was immediately sent for analysis. Saliva collection was carried out using a dedicated kit at 8 p.m. (evening free salivary cortisol, EFSC). The obtained material was frozen at $-32^{\circ} \mathrm{C}$ and stored for further analysis. After collecting samples for MSC, ESC, UFC, and EFSC, 1 mg overnight dexamethasone suppression test (1mg ONDST) was performed. Eventually, 41 volunteers were included in the study, whose cortisol concentration in the $1 \mathrm{mg}$ ONDST were $<50 \mathrm{nmol} / \mathrm{L}$, and cortisol levels in serum, saliva, and urine were within reference ranges (Tab. 1).

The hair sampling technique consisted of cutting off approximately 100 hair strands from the posterior vertex area of the head with a sterile scalpel close to the scalp. Next, $1 \mathrm{~cm}$ hair fragments were cut away close to their follicles, and after weighing $20 \mathrm{mg}$ samples they were sealed in paper envelopes until further analysis. In HCC assessment, the hair samples were placed into a $10 \mathrm{ml}$ plastic tube and flushed with methanol. Next, they were transferred into $5 \mathrm{ml}$ tubes and incubated at $50^{\circ} \mathrm{C}$ in methanol for 24 hours. The extract was transferred into a $3 \mathrm{~mL}$ tube for methanol evaporation. Subsequently, the residue was dissolved in $250 \mu \mathrm{L}$ of phosphate buffered saline (PBS) by incubation for 1 hour and sent for cortisol

Table 1. Reference ranges of the laboratory assay

\begin{tabular}{lc}
\hline Assay & Reference ranges \\
\hline $1 \mathrm{mg}$ ONDST & $<50 \mathrm{nmol} / \mathrm{L}$ \\
\hline Morning serum cortisol & $138-690 \mathrm{nmol} / \mathrm{L}$ \\
\hline Evening serum cortisol & $55-331 \mathrm{nmol} / \mathrm{L}$ \\
\hline Evening free salivary cortisol & $1.10-11.32 \mathrm{nmol} / \mathrm{L}$ \\
\hline Urine free cortisol & $138-524 \mathrm{nmol} / 24 \mathrm{hr}$ \\
\hline Hair cortisol concentration & Not validated \\
\hline
\end{tabular}

$1 \mathrm{mg}$ ONDST — $1 \mathrm{mg}$ overnight dexamethasone suppression test 
Table 2. Characteristics of the population. Data presented as mean \pm standard deviation (SD) and median \pm interquartile range (IQR)

\begin{tabular}{|c|c|c|c|c|}
\hline Variable & $\begin{array}{c}\text { Total } \\
(n=41)\end{array}$ & $\begin{array}{l}\text { Female } \\
(n=29)\end{array}$ & $\begin{array}{c}\text { Male } \\
(n=12)\end{array}$ & p value \\
\hline Age (years) & $62.97 \pm 10.92$ & $63.65 \pm 9.78$ & $61.33 \pm 13.64$ & 0.56 \\
\hline $1 \mathrm{mg}$ ONDST [nmol/L] & $\begin{array}{c}34.49 \pm 6.32 \\
(28 \pm 8)\end{array}$ & $\begin{array}{c}33.41 \pm 6.94 \\
(30 \pm 9)\end{array}$ & $\begin{array}{c}30.25 \pm 3.88 \\
(28 \pm 3)\end{array}$ & 0.07 \\
\hline Morning serum cortisol [nmol/L]) & $329.5 \pm 108.7$ & $318.1 \pm 109.6$ & $357.1 \pm 106$ & 0.3 \\
\hline Evening serum cortisol [nmol/L] & $110.5 \pm 48.68$ & $114.9 \pm 48.78$ & $99.67 \pm 48.78$ & 0.37 \\
\hline Urine free cortisol [nmol/24 hr] & $207.7 \pm 130.1$ & $213.1 \pm 130.4$ & $194.7 \pm 134.1$ & 0.69 \\
\hline $\begin{array}{l}\text { Evening free salivary cortisol } \\
\text { [nmol/L] }\end{array}$ & $\begin{array}{c}2.09 \pm 1.18 \\
(1.78 \pm 0.99)\end{array}$ & $\begin{array}{c}2.07 \pm 1.21 \\
(1.83 \pm 0.91)\end{array}$ & $\begin{array}{c}2.16 \pm 1.18 \\
(1.71 \pm 1.55)\end{array}$ & 0.99 \\
\hline $\begin{array}{l}\text { Hair cortisol concentration } \\
{[\mathrm{nmol} / \mathrm{mg}]}\end{array}$ & $\begin{array}{l}0.81 \pm 0.48 \\
(0.65 \pm 0.3)\end{array}$ & $\begin{array}{c}0.70 \pm 0.28 \\
(0.65 \pm 0.26)\end{array}$ & $\begin{array}{c}1.08 \pm 0.73 \\
(0.78 \pm 0.75)\end{array}$ & 0.19 \\
\hline
\end{tabular}

$1 \mathrm{mg}$ ONDST — $1 \mathrm{mg}$ overnight dexamethasone suppression test

measurement. Finally, HCC obtained in the samples was calculated for $1 \mathrm{mg}$ hair specimens ( $\mathrm{nmol} / \mathrm{mg}$ ).

All cortisol assessments were performed in the Central Clinical Laboratory of the Medical University of Gdansk, Poland. Commercial ELISA kit (IBL International GmbH, Hamburg, Germany, catalogue number RE 52611) was used for the MSC, ESC, EFSC, and HCC measurements. According to the manufacturer's data, cross-reactivity was determined to be $30 \%$ for prednisolone, $7 \%$ for 11-desoxycortisol, $4.2 \%$ for cortisone, $2.5 \%$ for prednisone, $1.4 \%$ for corticosterone, and $<1 \%$ for other test substances. The detection threshold was set at $0.138 \mathrm{nmol} / \mathrm{L}$, with functional sensitivity set at $0.828 \mathrm{nmol} / \mathrm{L}$. The intra and interassay coefficient of variation was determined at $7.3 \%$ for concentrations $7.452 \mathrm{nmol} / \mathrm{L}$ and $8.8 \%$ for concentrations $14.904 \mathrm{nmol} / \mathrm{L}$ (saliva), and $9.9 \%$ for concentrations $49.68 \mathrm{nmol} / \mathrm{L}$ and $20 \%$ for concentrations $41.4 \mathrm{nmol} / \mathrm{L}$ (serum). Urine free cortisol determinations were made with the set from the same manufacturer (IBL International GmbH, Hamburg, Germany, catalogue number RE52241). In UFC measurements, cross-reactivity was determined at $18.7 \%$ for 11-alpha-desoxycortisol, $10.8 \%$ for cortisone, $2.4 \%$ for corticosterone, and $<0.1 \%$ for the other substances. The declared intra assay variation was $7 \%$, and the inter assay variation was $<9 \%$. Cortisol measurements in saliva and hair were done twice, and arithmetic average values were used in statistical analysis.

\section{Results}

The assessment of variable distribution was performed by using the quantile-quantile plots. The t-test and the Mann-Whitney U test were used for comparisons between subgroups. Correlations were analysed by the Spearman test. The general linear model was fitted to perform multivariate analysis. Some variables were transformed before inclusion into the linear model. Values of $\mathrm{p}<0.05$ were considered to be statistically significant. R Studio software (RStudio Inc., Boston, USA, ver. 1.2.1335) was employed for the statistical analysis.

The values had a normal distribution for: age $(p=0.5999)$, MSC $(p=0.3008)$, ESC $(p=0.3725)$, and UFC ( $p=0.6905)$. A non-normal distribution was detected for: $1 \mathrm{mgONDST}(\mathrm{p}=0.2741)$, EFSC $(\mathrm{p}=0.9886)$, and HCC $(p=0.1873)$. HCC ranged from 0.3036 to 2.65 $\mathrm{nmol} / \mathrm{mg}$, and the average value was $0.8125 \pm 0.4834$ $\mathrm{nmol} / \mathrm{mg}$. The characteristics of the studied group are presented in Table 2 .

No significant correlations were found between HCC and EFSC (rho $=0.1005, \mathrm{p}=0.532$ ), HCC and MSC (rho $=0.04419, \mathrm{p}=0.7838$ ), HCC and ESC (rho $=-0.2071, \mathrm{p}=0.1938)$, and HCC and UFC $($ rho $=0.1793, p=0.262)$ (Fig. 1).

The general linear model was fitted to perform multivariate analysis. The dependent variable was the concentration of cortisol in the hair. Independent variables for the model were selected by the step method based on the AIC (Akaike Information Criterion) values. However, a statistically significant linear regression model could not be fitted.

\section{Discussion}

Several publications have indicated a strong relationship between serum cortisol and salivary cortisol [6, 30-34]. It is a result of the simultaneous cortisol secretion into the blood by the adrenal glands and subsequent cortisol diffusion from blood into saliva. Hence, salivary cortisol correlates with cortisol concentrations in blood at a given time point. On the other hand, correlations of HCC with cortisol concentrations in blood, urine, or saliva have been assessed as moderate or weak [35]. Our results have shown no correlation between HCC and cortisol concentrations in saliva, urine, and blood. The passive diffusion of free cortisol from the blood into the hair bulb is the main mechanism of the presence of cortisol in hair. Thus, HCC reflects the average concentration of serum cortisol over a given period of time depending on the length of hair used for analysis. Indeed, statistically significant correlations between HCC and multi-point measurements of urine and salivary cortisol have been reported [35-38]. Our 


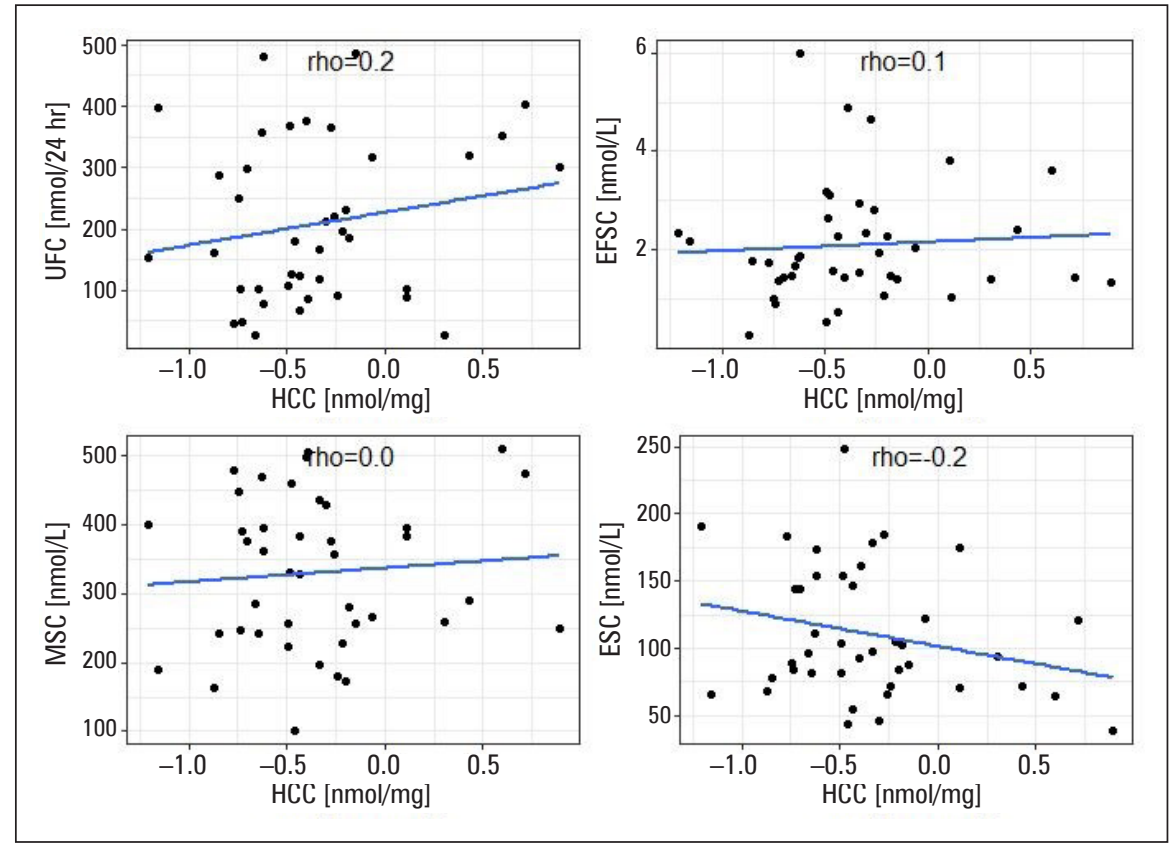

Figure 1. Correlation analysis between hair cortisol concentration (HCC) vs. urinary free cortisol (UFC), evening free salivary cortisol (EFSC), morning serum cortisol (MSC), and evening serum cortisol (ESC). rho - Spearman's rank correlation coefficient

results are in turn consistent with a number of studies assessing the relationship between HCC and single point cortisol measurement in saliva and serum where such correlations were weak or absent [36, 38, 39]. In our opinion, despite progress in laboratory diagnostics, including cortisol assays, it is still challenging to transfer complex regulation of cortisol production in vivo to relatively simple statistical models based on laboratory tests. Cortisol is secreted in a pulsating manner that is subject to circadian rhythms, and negative and positive feedback may depend on exogenous factors and numerous genetic variants determining the sensitivity of the cortisol receptor, which in turn, might alter its level and impact on clinical manifestations [6]. This may lead to misinterpretation of laboratory results and incorrect diagnosis [8,9]. Another problem raised by many other authors is the lack of sufficient validation of studies assessing the correlation of HCC with other biological samples $[20,36,40]$. Additionally, the possibility of pre-analytical errors, especially for more complex determinations such as HCC, should be taken into account.

For instance, the impact of substances used in hair care has not been fully evaluated. Interestingly, we did not see any difference in HCC between males and females despite the fact that the latter population probably use substances such as hair bleach more frequently.

Unlike other studies, our enrolment protocol was based on a preliminary assessment of cortisol levels in routine laboratory determinations of saliva, blood, and urine. Therefore, a number of external factors af- fecting the HPA axis were eliminated, such as social status, anthropometric parameters, or emotional state [41-44]. The impact of these factors is prominent [22]. Assessed cortisol levels reflected various time intervals: minutes and hours (blood, saliva), hours and days (urine), and days and months (hair). Such a wide time slot of determination of cortisol concentrations may better reflect the variability of its concentrations in analysed individuals. Additionally, we assessed the patients' clinical status during the year preceding enrolment in the study. The studied group was not large; however, it was homogeneous in terms of hormonal status.

The study has one major limitation, which is that a relatively small population was studied. This was due to the protocol of the study, which included strict exclusion criteria. Any potential factors that might have impacted the HPA axis excluded individuals from the study. Hence, we tested only individuals with no HPA axis impairment. The enrolment was performed in a hospital where many patients are given to steroid treatment or suffer from diseases impacting glucocorticosteroids levels. However, the studied population was small, it was very carefully selected, and represented individuals with no disorders of the HPA axis, which is a major advantage of our study. We believe that if the correlation across saliva, blood, and hair cortisol was strong, it would be displayed even in a relatively small population. Indeed, our data are consistent with other studies showing no such correlations. 


\section{Conclusion}

In summary, this work represents another stage in the discussion on the application of HCC determinations in clinical practice. The studied group was not large, but it was homogeneous in terms of hormonal status (HPA axis disorders were excluded). Our results showed no correlation between HCC and single point cortisol assessment in blood, saliva, and urine in patients with reference cortisol levels. Further analyses of HCC in healthy individuals vs. hyper/hypocortisolaemia patients are needed in order to assess efficient HCC cut-off points for HPA axis disorders.

\section{Competing interests}

The authors declare that they have no conflict of interest.

\section{Funding}

No funding was obtained for this study.

\section{Authors' contributions}

All authors made substantial contributions to the concept and designed of the study, L.C. - collection/assembly of data and writing the article, J.J. — critical revision of the article; PW - data analysis and interpretation; PK - collection of data, S.K. — research concept and design. All authors reviewed the manuscript and approved its final version.

\section{References}

1. Haddad RA, Giacherio D, Barkan AL. Interpretation of common endocrine laboratory tests: technical pitfalls, their mechanisms and practical considerations. Clin Diabetes Endocrinol. 2019; 5: 12, doi: 10.1186/s40842-019-0086-7, indexed in Pubmed: 31367466.

2. Pasternak-Pietrzak K, Moszczyńska E, Jurkiewicz E, et al. Paediatric Cushing's disease - a literature review of epidemiology, pathogenesis, clinical symptoms, and diagnostics. Endokrynol Pol. 2020; 71(1): 87-95, doi: 10.5603/EP.a2019.0040, indexed in Pubmed: 32129467.

3. Putignano P, Bertolini M, Losa M, et al. Screening for Cushing's syndrome in obese women with and without polycystic ovary syndrome. J Endocrinol Invest. 2003; 26(6): 539-544, doi: 10.1007/BF03345217, indexed in Pubmed: 12952368.

4. Fichna M, Fichna P. Glucocorticoids and beta-cell function. Endokrynol Pol. 2017; 68(5): 568-573, doi: 10.5603/EP.2017.0060, indexed in Pubmed: 29168546.

5. Cyrańska-Chyrek E, Szczepanek-Parulska E, Stajgis P, et al. Distinct clinical picture of Cushing's syndrome in a patient with Morris' syndrome - first literature report. Endokrynol Pol. 2020; 71(1): 96-97, doi: 10.5603/EP.a2019.0042, indexed in Pubmed: 31566248

6. Levine A, Zagoory-Sharon O, Feldman R, et al. Measuring cortisol in human psychobiological studies. Physiol Behav. 2007; 90(1): 43-53, doi: 10.1016/j.physbeh.2006.08.025, indexed in Pubmed: 17055006.

7. Gatti R, Antonelli G, Prearo M, et al. Cortisol assays and diagnostic laboratory procedures in human biological fluids. Clin Biochem. 2009, 42(12): 1205-1217, doi: 10.1016/j.clinbiochem.2009.04.011, indexed in Pubmed: 19414006.

8. Abdulateef DS, Mahwi TO. Assessment of hair cortisol in euthyroid, hy pothyroid, and subclinical hypothyroid subjects. Endocrine. 2019; 63(1): 131-139, doi: 10.1007/s12020-018-1743-9, indexed in Pubmed: 30191442

9. Cieszyński Ł, Berendt-Obołończyk M, Szulc M, et al. Cushing's syndrome due to ectopic ACTH secretion. Endokrynol Pol. 2016; 67(4): 458-471, doi: 10.5603/EP.a2016.0055, indexed in Pubmed: 27387249.

10. Meulenberg PM, Hofman JA. The effect of oral contraceptive use and pregnancy on the daily rhythm of cortisol and cortisone. Clin Chim
Acta. 1990; 190(3): 211-221, doi: 10.1016/0009-8981(90)90175-r, indexed in Pubmed: 2253401.

11. Stalder T, Kirschbaum C, Kudielka BM, et al. Assessment of the cortisol awakening response: Expert consensus guidelines. Psychoneuroendocrinology. 2016; 63: 414-432, doi: 10.1016/j.psyneuen.2015.10.010, indexed in Pubmed: 26563991.

12. Fries E, Dettenborn L, Kirschbaum C. The cortisol awakening response (CAR): facts and future directions. Int J Psychophysiol. 2009; 72(1): 67-73, doi: 10.1016/j.ijpsycho.2008.03.014, indexed in Pubmed: 18854200.

13. Hellman L, Nakada F, Zumoff B, et al. Renal capture and oxidation of cortisol in man. J Clin Endocrinol Metab. 1971; 33(1): 52-62, doi: 10.1210/jcem-33-1-52, indexed in Pubmed: 5558042.

14. Viardot A, Huber P, Puder JJ, et al. Reproducibility of nighttime salivary cortisol and its use in the diagnosis of hypercortisolism compared with urinary free cortisol and overnight dexamethasone suppression test. J Clin Endocrinol Metab. 2005; 90(10): 5730-5736, doi: 10.1210/jc.2004-2264, indexed in Pubmed: 16014408

15. Raul JS, Cirimele V, Ludes B, et al. Detection of physiological concentrations of cortisol and cortisone in human hair. Clin Biochem. 2004 37(12): 1105-1111, doi: 10.1016/j.clinbiochem.2004.02.010, indexed in Pubmed: 15589817.

16. Wennig R. Potential problems with the interpretation of hair analysis results. Forensic Sci Int. 2000; 107(1-3): 5-12 doi: 10.1016/s0379-0738(99)00146-2, indexed in Pubmed: 10689559.

17. Gow R, Thomson S, Rieder M, et al. An assessment of cortisol analysis in hair and its clinical applications. Forensic Sci Int. 2010; 196(1-3): 32-37, doi: 10.1016/j.forsciint.2009.12.040, indexed in Pubmed: 20096513.

18. Henderson GL. Mechanisms of drug incorporation into hair. Forensic Sci Int. 1993; 63(1-3): 19-29, doi: 10.1016/0379-0738(93)90256-a, indexed in Pubmed: 8138221.

19. Wosu AC, Valdimarsdóttir U, Shields AE et al Correlates of cortisol in human hair: implications for epidemiologic studies on health effects of chronic stress. Ann Epidemiol. 2013; 23(12): 797-811.e2, doi: 10.1016/j. annepidem.2013.09.006, indexed in Pubmed: 24184029.

20. Stalder T, Steudte-Schmiedgen S, Alexander N, et al. Stress-related and basic determinants of hair cortisol in humans: A meta-analysis. Psychoneuroendocrinology. 2017; 77: 261-274, doi: 10.1016/j. psyneuen.2016.12.017, indexed in Pubmed: 28135674.

21. Staufenbiel SM, Penninx BW, Spijker AT, et al. Hair cortisol, stress exposure, and mental health in humans: a systematic review. Psychoneuroendocrinology. 2013; 38(8): 1220-1235, doi: 10.1016/j.psyneuen.2012.11.015 indexed in Pubmed: 23253896.

22. Dettenborn L, Tietze A, Kirschbaum C, et al. The assessment of cortisol in human hair: associations with sociodemographic variables and potential confounders. Stress. 2012; 15(6): 578-588, doi: 10.3109/10253890.2012.65 4479, indexed in Pubmed: 22356099.

23. Gerber M, Jonsdottir IH, Kalak N, et al. Objectively assessed physical activity is associated with increased hair cortisol content in young adults. Stress. 2013; 16(6): 593-599, doi: 10.3109/10253890.2013.823599, indexed in Pubmed: 23855828

24. Garcia-Leon MA, Peralta-Ramirez MI, Arco-Garcia L, et al. Hair cortisol concentrations in a Spanish sample of healthy adults. PLoS One. 2018; 13(9): e0204807, doi: 10.1371/journal.pone.0204807, indexed in Pubmed: 30265722.

25. Kristensen SK, Larsen SC, Olsen NJ, et al. Hair dyeing hair washing and hair cortisol concentrations among women from the healthy start study. Psychoneuroendocrinology. 2017; 77: 182-185, doi: 10.1016/j. psyneuen.2016.12.016, indexed in Pubmed: 28073090.

26. Ito N, Ito T, Kromminga A, et al. Human hair follicles display a functiona equivalent of the hypothalamic-pituitary-adrenal axis and synthesize cortisol. FASEB J. 2005; 19(10): 1332-1334, doi: 10.1096/fj.04-1968fje, indexed in Pubmed: 15946990.

27. Slominski R, Rovnaghi CR, Anand KJS. Methodological Considerations for Hair Cortisol Measurements in Children. Ther Drug Monit. 2015; 37(6): 812-820, doi: 10.1097/FTD.0000000000000209, indexed in Pubmed: 25811341.

28. Russell E, Kirschbaum C, Laudenslager ML, et al. Toward standardization of hair cortisol measurement: results of the first international interlaboratory round robin. Ther Drug Monit. 2015; 37(1): 71-75, doi: 10.1097/FTD.0000000000000148, indexed in Pubmed: 25387254

29. Cieszyński Ł, Jendrzejewski J, Wiśniewski P, et al. Hair cortisol concentration in a population without hypothalamic-pituitary-adrenal axis disorders. Adv Clin Exp Med. 2019; 28(3): 369-373, doi: 10.17219/acem/90038, indexed in Pubmed: 30516881

30. Umeda T, Hiramatsu R, Iwaoka T, et al. Use of saliva for monitoring unbound free cortisol levels in serum. Clin Chim Acta. 1981; 110(2-3): 245-253, doi: 10.1016/0009-8981(81)90353-3, indexed in Pubmed: 6261989.

31. Poll EM, Kreitschmann-Andermahr I, Langejuergen Y, et al. Saliva collection method affects predictability of serum cortisol. Clin Chim Acta. 2007; 382(1-2): 15-19, doi: 10.1016/j.cca.2007.03.009, indexed in Pubmed: 17449021 
32. Hellhammer DH, Wüst S, Kudielka BM. Salivary cortisol as a biomarker in stress research. Psychoneuroendocrinology. 2009; 34(2): 163-171, doi: 10.1016/j.psyneuen.2008.10.026, indexed in Pubmed: 19095358.

33. Gozansky WS, Lynn JS, Laudenslager ML, et al. Salivary cortisol determined by enzyme immunoassay is preferable to serum total cortisol for assessment of dynamic hypothalamic-pituitary-adrenal axis activity. Clin Endocrinol (Oxf). 2005; 63(3): 336-341, doi: 10.1111/j.1365-2265.200 5.02349.x, indexed in Pubmed: 16117823.

34. Arafah BM, Nishiyama FJ, Tlaygeh H, et al. Measurement of salivary cortisol concentration in the assessment of adrenal function in critically ill subjects: a surrogate marker of the circulating free cortisol. J Clin Endocrinol Metab. 2007; 92(8): 2965-2971, doi: 10.1210/jc.2007-0181, indexed in Pubmed: 17535998.

35. Short SJ, Stalder T, Marceau K, et al. Correspondence between hair cortisol concentrations and 30-day integrated daily salivary and weekly urinary cortisol measures. Psychoneuroendocrinology. 2016; 71: 12-18, doi: 10.1016/j.psyneuen.2016.05.007, indexed in Pubmed: 27235635.

36. Sauvé B, Koren G, Walsh G, et al. Measurement of cortisol in human hair as a biomarker of systemic exposure. Clin Invest Med. 2007; 30(5): E183-E191, doi: 10.25011/cim.v30i5.2894, indexed in Pubmed: 17892760.

37. Xie Q, Gao W, Li J, et al. Correlation of cortisol in 1-cm hair segment with salivary cortisol in human: hair cortisol as an endogenous biomarker. Clin Chem Lab Med. 2011; 49(12): 2013-2019, doi: 10.1515/CCLM.2011.706, indexed in Pubmed: 21902574.

38. Vanaelst B, Huybrechts I, Bammann K, et al. Intercorrelations between serum, salivary, and hair cortisol and child-reported estimates of stress in elementary school girls. Psychophysiology. 2012; 49(8): 1072-1081, doi: 10.1111/j.1469-8986.2012.01396.x, indexed in Pubmed: 22725679.

39. Steudte S, Kolassa IT, Stalder T, et al. Increased cortisol concentrations in hair of severely traumatized Ugandan individuals with PTSD. Psychoneuroendocrinology. 2011; 36(8): 1193-1200, doi: 10.1016/j. psyneuen.2011.02.012, indexed in Pubmed: 21411229.

40. Davenport MD, Tiefenbacher S, Lutz CK, et al. Analysis of endogenous cortisol concentrations in the hair of rhesus macaques. Gen Comp Endocrinol. 2006; 147(3): 255-261, doi: 10.1016/j.ygcen.2006.01.005, indexed in Pubmed: 16483573

41. Iglesias S, Jacobsen D, Gonzalez D, et al. Hair cortisol: A new tool for evaluating stress in programs of stress management. Life Sci. 2015; 141 188-192, doi: 10.1016/j.lfs.2015.10.006, indexed in Pubmed: 26454227.

42. Russell E, Koren G, Rieder M, et al. Hair cortisol as a biological marker of chronic stress: current status, future directions and unanswered questions. Psychoneuroendocrinology. 2012; 37(5): 589-601, doi: 10.1016/j. psyneuen.2011.09.009, indexed in Pubmed: 21974976.

43. Karlén J, Ludvigsson J, Frostell A, et al. Cortisol in hair measured in young adults - a biomarker of major life stressors? BMC Clin Pathol. 2011; 11: 12, doi: 10.1186/1472-6890-11-12, indexed in Pubmed: 22026917.

44. Wosu AC, Gelaye B, Valdimarsdóttir U, et al. Hair cortisol in relation to sociodemographic and lifestyle characteristics in a multiethnic US sample. Ann Epidemiol. 2015; 25(2): 90-5, 95.e1, doi: 10.1016/j.annepidem.2014.11.022, indexed in Pubmed: 25534254. 